\title{
Risk Level Assessment On Road Construction's Contractors Using Cultural - Professionalism Based Approach
}

\author{
Risk Level Assessment On Road Construction's Contractors Using Cultural - \\ Professionalism Based Approach \\ [ Basyar Bustan ${ }^{1}$, Lawalenna Sammang $^{2}$, Nurali $^{3}$, Isran Ramli ${ }^{4}$ ]
}

\begin{abstract}
This study is aimed to analyze the characteristics of potential risk, risk level, risk response and design a risk assessment models with multi-criteria on a road construction project. This study is done in the form of a survey by capturing the opinions or perceptions, experiences and attitudes of respondents implementing on road construction. Variables and indicators that are expected affecting the risk of road construction projects were modeled and tested using the methodology of Expert Choise to describe, quantify and demonstrate the level, allocation, and risk response on road construction projects with different risk variables. Results of the study, the first is the amount of the risk identified for the construction of the road as much as $\mathbf{2 8 1}$ risks and were grouped into aspect of non-technical 57, technical aspect 39, financial aspect 36, the cultural aspect of the construction 76, aspect of health and safety management 38 and environmental aspect 35 . The second is the weight of importance of objective indicators on the risk of road construction works, namely cost 0.370 , time 0.252, quality 0.184 , Health and safety management 0.120 , and environmental 0,074 . Weight of objective risk criteria of cost, to the risk of non-technical aspects 0,113 , technical aspect 0.247 , financial aspect 0.185 , cultural aspect of construction 0.304 , health and safety management aspect 0.083 and environmental aspect 0.068 . The third is the risk map, the extreme risk was 116 or $41.28 \%$, high risk was 153 or $54.45 \%$, medium risk was 12 or $4.27 \%$, and low risk was none. The fourth is the allocation of risk to the contractor was 53.19 or $55.88 \%$, share was 22.30 or $23.58 \%$ and the owner was 19.52 or $20.55 \%$. The fifth is an alternative strategy for handling the response risks road construction projects that risk retention as much as 36.03 or $38.73 \%$, risk reduction as much as 19.82 or $19.01 \%$, risk avoidance as much as $\mathbf{2 6 . 4 7}$ or $\mathbf{2 8 . 1 3 \%}$, and risk transfer as much as 16.90 or $15.17 \%$.
\end{abstract}

Keywords-- risk management, uncertainties, risk level, construction cultural, road contractors ${ }^{1}$ Doctoral Student, Department of Civil Engineering, Hasanuddin
Univeristy, Makassar, South Sulawesi, Indonesia,

${ }^{2}$ University of Hasanuddin, Faculty of Engineering, Jl.Perintis KemerdekaanKm 10 Makassar, South Sulawesi, Indonesia,

${ }^{3}$ University of Hasanuddin, Faculty of Engineering, Jl.Perintis Kemerdekaan Km 10 Makassar, South Sulawesi, Indonesia,

${ }^{4}$ University of Hasanuddin, Faculty of Engineering, Jl.Perintis KemerdekaanKm 10 Makassar, South Sulawesi, Indonesia,

\section{Introduction}

Currently, the population of Indonesia has reached \pm 252.165 million [1]. That number, which belongs to the labor force, reached 113.89 million people or around $49.13 \%$ of the entire population of Indonesia. Indonesia working population reached 104.87 million people or around $45.24 \%$ of the entire population in Indonesia. Most workers in Indonesia are working in the informal sector, that is 67.86 million and only 32.14 million are working in the formal sector [2]. Number of contractors in South Sulawesi province are 6300 companies, consisting of 4092 small companies with $\mathrm{K} 1$ qualification or around $64.95 \%, 775$ companies with $\mathrm{K} 2$ qualification or around $12.30 \%, 538$ companies with health and safety qualification or around $8.54 \%, 613$ companies with M1qualification or $9.73 \%, 228$ medium-sized companies with M2 qualification or $3.62 \%$, 48 large companies with B1 qualification or $0.76 \%$, and 6 companies with $\mathrm{B} 2$ qualification or $0.10 \%$ [3].

The role of Infrastructure becomes very important in supporting the economic growth and development of the country. World Bank, emphasized the importance of the infrastructure in the country's development, and how countries in the world to invest efficiently and effectively. Infrastructure development budget each year has increased. In 2014 the government budgeted around Rp188,7 trillion for infrastructure development. The budget rose to Rp4.4 trillion from the state budget in 2013 which was around Rp184,3 trillion. Compared to the total state spending in 2014, which reached Rp1.816,7 trillion, the infrastructure budget allocation got a portion of $10.4 \%$ [4].

The infrastructure sector development budget that comes from the state budget of 2014 which was allocated the Ministry of Public Works to South Sulawesi province reached Rp2.5 trillion. The budget was allocated to three units that managing the public works, respectively Department of Highways, Department of Spatial Planning and Housing and the Department of Water Resources Management. The budget allocation of $\mathrm{Rp} 2.5$ trillion was distributed to each of the Highways agency that was Rp 1 trillion, Distarkim was Rp 395 billion, and PSDA was Rp1.1 trillion. Infrastructure budget allocation from the state budget for Sulsel was increased compared to previous years, in 2009, it was Rp1.6 trillioin, in 2010 was Rp1.6 trillion, in 2011 was Rp1.9 trillion, 
in 2012 was $\mathrm{Rp} 2$ trillion, in 2013 was $\mathrm{Rp} 2.3$ trillion and in 2014 was Rp 2.5 trillion [4].

Throughout the years of 2010 - 2013, the government disbursed fund about Rp 4.564 trillion for road and bridge's construction in South Sulawesi, with details as follows: in 2010 was USD 722.31, year 2011 was Rp 826.53 billion, in 2012 was Rp 975, 71 billion, in 2013 was Rp 1.04 trillion, in 2014 was Rp 1.00 trillion. Estimated funding of RPJMN 20152019 for the road sector was Rp 340 trillion from the state budget, Rp 200 trillion from the local sate budget, Rp 65 trillion from the state-owned enterprises and Rp 200 trillion from the private sector with the target in the 2019 that the national road quality will reach $100 \%$ of standard quality road [4].

The quality of road construction indicates the amount of construction that is not in accordance with specifications, failure to achieve steady road conditions, and the design life of the road is not optimal, and the number of road construction project execution exceeds the execution time of the contract. National road quality is not stable in the Sulawesi region is likely to increase in the period 2005-2010. In 2010, of the total road length of $7426.84 \mathrm{~km}$ as many as $1,445 \mathrm{~km}$ condition is not steady (19.46 percent). The roads are not steady at 39.32 percent categorized as minor damage and 60.68 percent were severely damaged. National road quality is not steady in South Sulawesi province is likely to increase in the period 20052010. In 2010, of the total road length of $1066.5 \mathrm{~km}$ length of roads with steady state along $676.44 \mathrm{~km}$, or approximately $63.42 \%$, and as much as $390.21 \mathrm{~km}$ condition is not steady 36.58 percent. The roads are not steady at 13.86 percent categorized as minor damage and 86.14 percent were severely damaged. Well above the average of Sulawesi [4].

Considering this great budget, its spending should be implemented efficiently and effectively by strategic implementation of infrastructure development so that the efficiency and effectiveness of cost, time, quality, safety, and environmental and other objectives can be achieved optimally. If this is not achieved then it will result in huge losses. Infrastructure development, the same as the other projects, is always overshadowed by the risk of failure. The larger the infrastructure projects are handled, the greater the risk challenge is. Studies conducted at the University of Aalborg [5] shows that in its history, the large-scale infrastructure projects (known as mega projects) have a high potential to undergo cost overruns and various other risks [6].

Risk management in infrastructure development projects have been started, although generally is still very limited to the economic aspect, which is certainly not enough. The perpetrators in infrastructure projects should also be able to apply risk management in all aspects of the potential risks that may cause harm to the contractor. The Indonesian government has sought a way to implement risk management and has made a policy by issuing regulations to carry out a wide range of risk management in the framework of internal control of the government. Applying the Government Internal Control System (known as "SPIP"), as stipulated in Government Regulation No. 60 of 2008 as a guide in the control over the implementation of infrastructure public works and settlement, which includes five elements: environment control, risk assessment, control activities, information and communication, and monitoring internal control. [7]

To sharpen the implementation of risk management in any construction work, the minister of Public Works has instructed his staff in accordance with the instruction minister of Public Works No. 02 / IN / M / 2011. The instructions include the implementation of risk management through the process of establishing the context, risk identification, risk analysis, risk evaluation, risk management, monitoring and review, communication and consultation. Despite the fact that these instructions have not been implemented optimally and sustainably includes the road construction works.

Implementation of the project development activities in the construction services business faced with several constraints as well as the risk of a very major objective namely cost, time, quality and safety and the environment. The successful implementation of a project carried out by the construction company associated with the extent to which these risks can be well controlled.

One risk that is considered to be very influential in the construction industry in addition to technical and non technical aspects is the risk of corruption, this risk is categorized as a crime that is extraordinary (extraordinary crime), and this risk is prevalent in every stage of the project. Indication of the corruption during the process of these activities is some government projects which are not timely, well targeted, not right in quality and inefficient. As a result, the some constructions had failed and age construction plan was ineffective. Corruption that lasted so long would be very detrimental to the cultural construction. This corruption behavior can occur because of individual behavior aspect, organizational aspects of governance, aspects of the legislation, monitoring aspect, procurement aspect, and implementation aspect [8]. Study of the World Bank (World Bank) said that one of the obstacles of infrastructure development is corruption. In fact, corruption in infrastructure is very high in number, up to 40 per cent, (the Executive Director of the Institute for Development and Finance) [9]. Corruption Perception Index (CPI) 2012, released by Transparency International Indonesia (TII) shows the country is still not out of the culture of corruption that has been ingrained. It is seen from IPK of Indonesia which is slipped from 110 to 118 [10].

Another challenge for the construction industry is the health and safety risks. Labor during working activity is always interacting with hazardous factors that exist in the workplace; which can not be avoided by labor as jobs in the construction industry should be handled directly by the workforce, so that a common problem is the emergence of occupational health and safety problem such as accident at the workplace.

Every year around the world, 2 million people die by work-related problems. This number, 354000 people suffered fatal accidents. Ironically, every year there are 270 million workers who suffered occupational accidents and 160 million 
occupational diseases. Costs for occupational hazard are huge. The ILO estimates that the losses suffered as a result of accidents and occupational diseases each year more than US $\$ 1.25$ trillion, equal to $4 \%$ of the Gross Domestic Product (GDP). The rate of fatal accidents in developing countries is four times higher than in industrialized countries. Most accidents and occupational diseases occur in developing countries, especially in agriculture, fishing and logging, mining and construction (ILO, 2003). Research carried out the world (ILO) concluded that each day on average 6000 people are died, equivalent to every 15 seconds one person dies or 2.2 million people per year due to sickness and accidents related to their work. Male workers who died, two times more than female workers, because they are more likely to perform dangerous jobs [11].

Research of World Economic Forum in 2006 stated that the number of deaths due to accidents in Indonesia reachs 718 for every 100,000 workers, not to mention the calculated losses and the consequences of the accident, both for managers and project implementers as well as workers and families [12].

Results of the research on occupational accidents in the construction industry have showed that the risk of workplace accidents becomes very important note to be controlled. Occupational health and safety risks are necessary to be observed in order to achieve successful implementation of construction projects. Occupational health and safety risks and the impact on labor, government actually has drawn up regulations in the form of legislation to the implementation guidelines health and safety [13] of the construction of public works. The problem is that the parties concerned have not been optimally implementing these rules consistently. The service provider has not made a major consideration in controlling the risk of occupational accident in any work carried out.

Other problem that often occurs in road construction is a matter of environmental risks. Construction of road and bridge infrastructure aimed to support the distribution of goods and human traffic and form a spatial structure (Strategic Plan 2010-2014 of the Ministry of Public Works). Infrastructure development has two sides that should be noted, they are aspect of development objectives and impact. Any development activity that undertaken certainly have an impact on the environment by both positive and negative impact, the one that should be considered is how to carry out the construction to obtain maximum results and benefits with the negative impact on the environment is minimum.

Government, in this case is the public works department has a lot of issuing regulations and guidelines for environmental management of roads (General Guidelines for Management of road and bridge construction are environmentally sound) [14], but the problem is the management of environmental risks in road construction works have not been planned and implemented well.

Considering the high risk potential results obtained from research study and a huge investment and the impact on the parties associated in the project, it is very necessary to study the contractor's risk assessment models of road construction which integrates behavior and professionalism.

\section{A. Risk Definition}

All construction activities inevitably face many risks either directly or indirectly [15]. Risk is the chance of something happens in circumstances, events, incidents in the process of business activities, which could be impacting negatively on the achievement of business objectives that have been set. Risk is a condition where there is a possibility of profit or economic or financial loss, damage or physical injury, or delay, as a consequence of the uncertainty over the work implemetation [16].

The concept of risk in construction projects is a measure of the probability and the consequences of not reaching a predetermined target project. Risk is the cumulative effect of the occurrence of an uncertain event that is detrimental affect on project objectives. The risk is an occurrence of a process, which management cannot be surely calculated both with its impact and magnitude of the the impact [17].

Uncertainty is a condition where there is a lack of knowledge, information, or an understanding of the decision and its consequences. The higher the level of the uncertainty, the higher the risk is [18]. Risk arises because of the uncertainty, because uncertainty will result in hesitance [19].

Risk extends along between two extremes, namely the full information and no information at all. The extreme end of the most risky is no information at all, or so-called unknown-unknown, in such conditions occur uncertainty in total, while the ends of the least risky is the complete information or called known, in these conditions occurs uncertainties total, while the the middle condition when some informations are be availabel or called knownunknown, and in this condition occurs two circumstances, namely the uncertainty in general but there is no certainty to any particular case. Occurrences in the future can not be known with certainty. If a good condition happens then it is a good chance (opportunity), but if bad thing happens it will be a risk [15].

\section{B. Risk Management}

Risk management is an activity undertaken to respond to risks that have been known to minimize the adverse consequences that may arise. Definition of risk management as all series of activities related to risk, could include risk management planning, risk identification, risk analysis, management and monitoring of risks. Risk management is an organized approach to find potential risks as to reduce the occurrence of unexpected things and its unxpected bad impacts can be known [20].

Risk management process is a preventive action where the real business conditions may become clear in advance and a greater failure can be avoided. Through risk management, we will know the proper method to avoid or 
reduce the magnitude of the losses suffered as a result of the risk. Uncertainties in a business can be a chance (opportunity) or risk, which can bring profits or losses. Risk maps could be done by entering the mean probability and mean impact matrix into a matrix form (Fig.1). In the matrix, probability values were expressed into the Y-axis, while values were expressed into the impact of the value of $\mathrm{X}$, both of depicted in a scale of 1-5 (started from the small number, number $1=$ lowest $5=$ highest numbers).

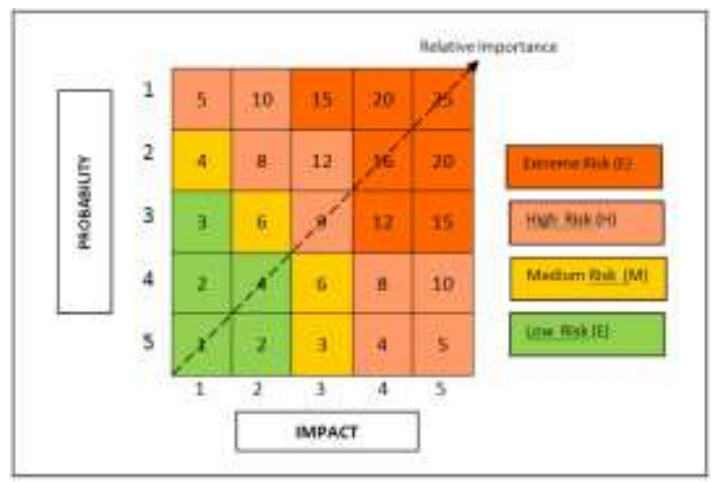

Figure 1. Risk map

Risk identification is the selection of risk that may have an impact on the project and document storage based on their characteristics. Risk identification serves to get areas and technical processes that have a potential risk for subsequent analysis.

Risk analysis with the impact probability matrix is made in the following categories; low risk (L), control and monitoring, adequate with the normal act, moderate risk (M) requires identification and control of all the factors that contributed to a reassessment of the condition of project monitoring stages, high risk $(\mathrm{H})$ may delay the project schedule or significantly affect the technical performance and cost, and risk management is needed, as well as extreme risk (E), the events that may lead to a failure, unacceptable costs swelling, schedule delays which result in a project failure.

Risk allocation is the risk-sharing projects with the basic principle that the risk is shared and imposed to the most competent party to manage the risks. The allocation of risk includes the sharing of project risks between the contractor and the owner based on the principle of risk allocation. The principle of risk allocation is that the most able party to control a certain risk should also bear the risk.

Risk response, after a risk analysis then a risk management strategy is made, that is; avoiding the risk (risk avoidance), when the impact is very large and massive, and the company is not being able to control it, the risk is transferred (risk transfer), if the risk can be covered by others, either through insurance or submitted subcontractor specialists, the risk had reduced by itself (risk reduction), if the company is confident of being able to control with some careful planning. Risk reduction could be done by reducing its likelihood, reduce its impact or both. Risk is acceptable (risk retention), if the impact is not much large, and still worthy of inclusion as a cost [21].

\section{Analytical Hierarchy Process}

The basic principle of Analytical Hierarchy Process according to Saaty (1993), the basic principle in the process of preparing the model in AHP analytic hierarchy:

\section{Problem Decomposition}

In the preparation of this hierarchy, it is necessary to breakdown the whole issue into several elements / components and then from the component, hierarchy is made. Solving these elements is conducted until the elements can no longer be devided, in order to get some levels of a problem. Preparation of the hierarchy is an important step in the analysis model hierarchy. The steps of the preparation of this hierarchy are ; identification of the overall objectives and sub-objectives, search for criteria to obtain sub-objectives of the overall goal, composing sub-criteria of each criteria, where each criterion and sub-criteria must be specific and indicate the level of the parameter value or verbal intensity, determining the actors involved, the actors of the policy, determining the alternative as the output destination which its priority will be determined.

\section{Comparative Judgement}

This principle is done by making judgments about the pairwise comparison of the relative importance of the two elements at a certain hierarchical level in relation to the rate on it and gives a numerical weight based on the comparison. Results of this study are presented in a matrix called pairwise comparison.

\section{Synthesis of Priority}

Synthesis is the stage to get the weight of each hierarchy and alternative element. Because the pairwise comparison matrix contained in each level to get a global priority, then synthesis should be conducted in stages at each local priority. A procedure for implementing the synthesis is different with the form of hierarchy. While sorting the elements according to the relative importance through the synthesis procedure is called priority setting.

\section{Logical Consistency}

Consistency has two meanings or similar objects. Consistency of data obtained from ratio consistency (CR) which is the quotient between the consistency index $(\mathrm{Ci})$ and the random index $(\mathrm{Ri})$.

\section{Conceptual Framework}

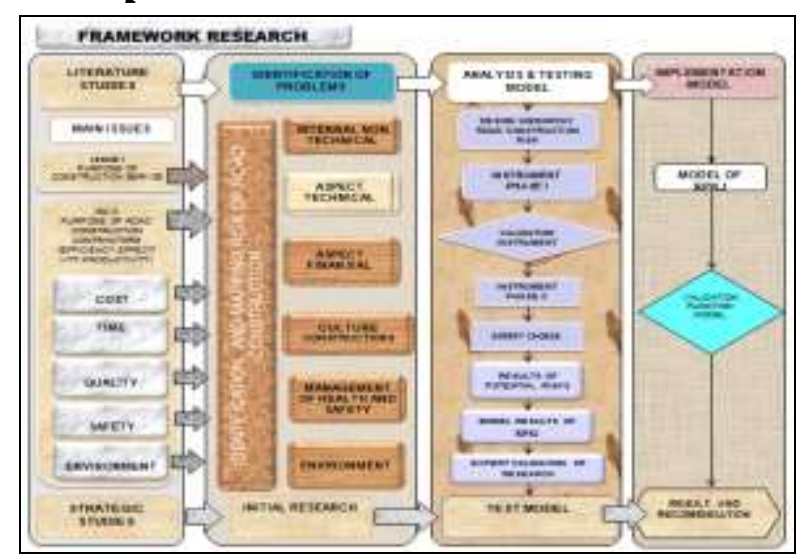

Figure 2. Conceptual framework of the research 


\section{Research Methodology}

\section{A. Location and Time of the Research}

This research had been conducted in the province of South Sulawesi. The sample to be studied is the contractor in a road construction project. This research was conducted at the provider, in this case is the contractor in the field of road transport services with contractor qualification of medium scale (M1 and M2) and high (B1 and B2) with the number of 95 respondents.

\section{B. Research Design}

Conducting survey, literature review and risk identification, performing initial testing that supports the topic of risk management on road construction projects, drafting the models and research instrument (hierarchy of implementer risk of road construction), Figure 3, performing risk management analysis on the project road construction; risk identification, risk analysis, risk response, control of risk, and the results and recommendations.

Solving the problem of road construction risks by using AHP takes the following steps; define problems and set goals, organize the problem into a hierarchical structure so that complex problems can be seen in detail and measurable, set priorities for each element of the problem in each hierarchy. This priority is generated from a matrix of pairwise comparisons between all elements at the same hierarchical level, to test the consistency of the comparison between elements obtained at each level of the hierarchy deviation of consistency which is expressed in an index of consistency [22].

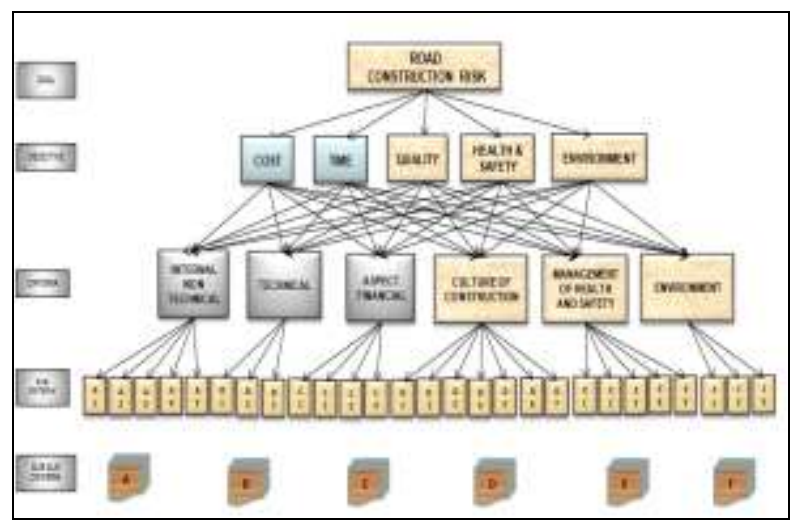

Figure 3. Hierarchy of implementer risk of road construction

$$
C I=\frac{\lambda_{\text {maks }^{-n}}}{n-1}
$$

Where:

$$
\begin{array}{ll}
\mathrm{n} & =\text { matrix size } \\
\lambda_{\text {maks }} & =\max \text { eigenvalue }
\end{array}
$$

Consistency index (C1), random matrix with research scale 1 to 9 , and its opposite as random index (R1). Based on the calculation of Saaty with 500 samples, if the numerical judgments had taken randomly from the scale $1 / 9,1 / 8, \ldots, 1,2, \ldots, 9$, the average consistency for different size of matrix would be obtained.

$$
\mathrm{CR}=\mathrm{CI} / \mathrm{RI}
$$

$$
\begin{aligned}
& \text { Where: } \\
& \text { CR = Consistency Ratio } \\
& \text { CI = Consistency Index } \\
& \text { RI = Random Index }
\end{aligned}
$$

Table 1 The relation between matrix size and RI

\begin{tabular}{|c|c|}
\hline Matrix size & RI value \\
\hline 1,2 & 0,00 \\
\hline 3 & 0,58 \\
\hline 4 & 0,90 \\
\hline 5 & 1,12 \\
\hline 6 & 1,24 \\
\hline 7 & 1,32 \\
\hline 8 & 1,41 \\
\hline 9 & 1,45 \\
\hline 10 & 1,49 \\
\hline 11 & 1,51 \\
\hline 12 & 1,58 \\
\hline
\end{tabular}

\section{Results And Discussion}

\section{A. Risk Identification}

A number of risks were identified for the road construction as much as 281 risks and were grouped into non-technical aspect 57 risks, technical aspects 39 risks, financial aspect 36 risks, cultural construction aspect 76 risks, health and safety management aspect 38 risks and environmental aspect 35 risks.

\section{B. Assessment and weight level of risk}

Table 2. Weight of objective risk

\begin{tabular}{|c|l|c|c|}
\hline NO & \multicolumn{1}{|c|}{ Objective risk } & weight & Rank \\
\hline 1 & Cost & 0,370 & 1 \\
\hline 2 & Time & 0,252 & 2 \\
\hline 3 & Quality & 0,184 & 3 \\
\hline 4 & Health and safety Management & 0,120 & 4 \\
\hline 5 & Environment & 0,074 & 5 \\
\hline
\end{tabular}

Weights of objective interest level of the indicator at risk on road construction work are cost 0.370 , time 0.252 , quality 0.184, health and safety management 0.120, and environmental 0.074 , see table 2 .

Results of priority risk analysis by weighting each criterion is repectively for non-technical aspect $0.113,0.247$ for technical aspect, 0.185 for financial aspect 0.304 for construction 
Proc. of The Third Intl. Conf. On Advances in Civil, Structural and Mechanical Engineering - ACSM 2015 Copyright (C) Institute of Research Engineers and Doctors, USA .All rights reserved.

ISBN: 978-1-63248-083-5 doi: 10.15224/ 978-1-63248-083-5-94

cultural aspect, 0.083 for health and safety management aspect and 0.068 for environmental. It can be seen in Table 3 .

Table 3. Risk weighting criteria

\begin{tabular}{|c|l|c|c|}
\hline CODE & \multicolumn{1}{|c|}{ Criteria } & Weight & Rank \\
\hline A & Non-technical aspect & 0,113 & 4 \\
\hline B & Technical aspect & 0,247 & 2 \\
\hline C & Financial aspect & 0,185 & 3 \\
\hline D & Construction cultural aspects & 0,304 & 1 \\
\hline E & Health and safety management aspect & 0,083 & 5 \\
\hline F & Environmental aspect & 0,068 & 6 \\
\hline
\end{tabular}

Results of priority risk analysis with weight of each subcriteria are respectively 0.335 for $\mathrm{A} 1$ (Planning), 0.254 for $\mathrm{A} 2$ (Organizing), 0.083 for A3 (Briefing), 0.182 for A4 (Control), and 0.125 for A5 (Legal aspects). It can be seen in Table 4.

Table 4. Weight of subcriteria A non-technical aspect

\begin{tabular}{|c|l|c|c|}
\hline CODE & \multicolumn{1}{|c|}{ Sub criteria } & Weight & Rank \\
\hline A1 & Planning & 0,335 & 1 \\
\hline A2 & Organizing & 0,254 & 2 \\
\hline A3 & Directing & 0,083 & 5 \\
\hline A4 & Supervising and evaluating & 0,182 & 3 \\
\hline A5 & Legal aspect & 0,125 & 4 \\
\hline
\end{tabular}

Results of priority risks analysis with weight of each subcriteria are respectively 0.281 for B1 (Project characteristics), 0.150 for B2 (Owner characteristics), and 0,568 for B3 (Construction Implementation), see table 5.

Table 5. Weight of subcriteria and technical aspect

\begin{tabular}{|c|l|c|c|}
\hline CODE & \multicolumn{1}{|c|}{ Criteria } & Weight & Rank \\
\hline B1 & Project characteristics & 0,281 & 3 \\
\hline B2 & Owner characteristics & 0,150 & 2 \\
\hline B3 & Construction Implementation & 0,568 & 1 \\
\hline
\end{tabular}

Results of priority risks analysis with weight of each subcriteria are respectively 0.134 for $\mathrm{C} 1$ (Financial uncertainty and cash flow), 0.409 for C2 (Project costing), 0,201 for C3 (Market risk), and 0.256 for C4 (Fraud). It can be seen in Table 6.

Table 6. Weight of subcriteria $\mathrm{C}$ financial aspect

\begin{tabular}{|c|l|c|c|}
\hline CODE & \multicolumn{1}{|c|}{ Sub Criteria } & Weight & Rank \\
\hline C1 & Financial uncertainty and cash flow & 0,134 & 4 \\
\hline C2 & Project costing & 0,409 & 1 \\
\hline C3 & Market risk & 0,201 & 3 \\
\hline C4 & Fraud & 0,256 & 2 \\
\hline
\end{tabular}

Results of priority risk analysis with weight of each criteria are respectively 0.206 for D1 (Individual behaviour aspect), 0.315 for D2 (Governance organizational aspect), 0,050 for D3 (Law and regulation aspect), 0.091 for D4 (Supervision aspect), 0,146 for D5 (Procurement aspect), 0,074 for D6 (Implementation aspects), and 0.119 for D7 (Local features). It can be seen in Table 7 .
Table 7. Weight of subcriteria D cultural aspect of construction

\begin{tabular}{|c|l|c|c|}
\hline CODE & \multicolumn{1}{|c|}{ Sub Criteria } & Weight & Rank \\
\hline D1 & Individual behaviour aspect & 0,206 & 2 \\
\hline D2 & Governance organizational aspect & 0,315 & 1 \\
\hline D3 & Law and regulation aspect & 0,050 & 7 \\
\hline D4 & Supervision aspect & 0,091 & 5 \\
\hline D5 & Procurement aspect & 0,146 & 3 \\
\hline D6 & Implementation aspects & 0,074 & 6 \\
\hline D7 & Local features & 0,119 & 4 \\
\hline
\end{tabular}

Results of priority risk analysis with weight of each criteria are respectively 0.343 for E1 (Health and safety policy), 0.231 for E2 (Health and safety planning), 0.194 for E3 (Application and operating activities), 0.140 for E4 (examination), and 0.092 for E5 (Management review). It can be seen in Table 8.

Table 8. Weight of sub-criteria E healthy and safety management aspect

\begin{tabular}{|c|l|c|c|}
\hline CODE & \multicolumn{1}{|c|}{ Sub Criteria } & Weight & Rank \\
\hline E1 & Health and safety policy & 0,343 & 1 \\
\hline E2 & Health and safety planning & 0,231 & 2 \\
\hline E3 & Application and operating activities & 0,194 & 3 \\
\hline E4 & Examination & 0,140 & 4 \\
\hline E5 & Management review & 0,092 & 5 \\
\hline
\end{tabular}

Results of priority risk analysis with weight of each criteria are consecutively 0.179 for F1 (Preparation of construction works), 0.346 for F2 (Implementation of construction works), and 0.475 for F3 (in Work site base camp). It can be seen in Table 9.

Table 9. Weight of subcriteria F environmental aspect

\begin{tabular}{|c|l|c|c|}
\hline CODE & \multicolumn{1}{|c|}{ Sub Criteria } & Weight & Rank \\
\hline F1 & Preparation of Construction works & 0,179 & 3 \\
\hline F2 & Implementation of construction works & 0,346 & 2 \\
\hline F3 & In work site base camp & 0,475 & 1 \\
\hline
\end{tabular}

\section{The risk map}

Analisis results of risk management that have been done, the empirical findings obtained in this study are about 281 variables were identified, extreme risk was about 116 risks or $41.28 \%$, high risk was about 153 risks or $54.45 \%$, intermediate risk (medium risk) as much as 12 risks or $4.27 \%$, low risk (low risk) was not available. Around 57 subindicators were identified for non-technical risks are extreme risk as much as 16 risks or $28.07 \%$, high risk as much as 29 risks or $50.88 \%$, medium risk as much as 12 risks or $21.05 \%$, and low risk was not available. Around 39 sub-indicators were identified for technical risks are extreme risk as much as 24 risks or $61.54 \%$, high risk as many as 15 risks or $38.46 \%$, medium risk and low risk were not available. around 36 subindicators were identified for financial risks are extreme risk as much as 15 risks or $41.67 \%$, high risk as many as 21 eisks or $58.33 \%$, medium risk and low risk were not available. Around 76 sub-indicators were identified for construction cultural aspect are extreme risk as much as 45 risks or $59.21 \%$, high risk as many as 31 risks or $40.79 \%$ medium risk and low risk were not available. A total of 38 sub-indicators were identified for the 
risk management of health and safety are extreme risk as much as 10 risks or $26.32 \%$, high risk as many as 28 risks or $73.69 \%$ medium risk and low risk were not available. A total of 35 sub-indicators were identified for environmental aspect are extreme risk as much as 6 risks or $17.14 \%$, high risk as much as 29 risks or $82.86 \%$, medium risk and low risk were not available.

\section{Risk allocation}

Allocation risk of road construction works for the contractor as much as 53.19 or $55.88 \%$, divided around 22.30 or $23.58 \%$ and the owner as much as 19.52 or $20.55 \%$. The average allocation of risk (A) non-technical aspect of the contractor parties as much as 59.00 or at $61.95 \%$, shared around 20.60 or $21.99 \%$ and the owner as much as 15.40 or $16.12 \%$. The average allocation of risk (B) for technical aspect of the contractor parties as much as 49 or as much as $51.49 \%$, divided around 23.33 or $24.56 \%$ and the owner as much as 15.31 or $23.96 \%$. The average allocation of risk (C) financial aspect for the contractor as much as 65.75 or $69.06 \%$, shares around 18 or $18.85 \%$ and the owner as much as 11.25 or $12.09 \%$. The average risk allocation (D) for construction cultural aspect of the contractor parties as much as 36.43 or at $38.29 \%$, shared ar 24.57 or around $6.02 \%$ and the owner as much as 34 or $35.69 \%$. The average allocation of risk (E) healthy and safety management aspect for the contractor as much as 59.20 or $62.17 \%$, divided around 23.40 or $24.64 \%$ and the owner as much as 12.40 or $13.18 \%$. The average allocation of risk $(\mathrm{F})$ environmental aspec for the as much as 60.00 or $63.14 \%$, shared around 22.67 or $24.07 \%$ and the owner as much as 12.33 or $12.79 \%$.

\section{E. Risk response}

The alternative strategy of handling the response risk for road construction projects are bearing (retention) the risk with an achievement of as much as 36.03 or $38.73 \%$, decreasing (reduction) the risk as much as 19.82 or $19.01 \%$, avoiding (avoidance) the risk as much as 26.47 or $28.13 \%$, and transferring (transfer) the risk as much as 16.90 or at $15.17 \%$. The average alternative strategies for handling the risk response for (A) non-technical aspect are by bearing (retention) the risk with an achievement of as much as 39.57 or at $41.65 \%$, decreasing (reduction) the risk as much as 14.27 or $15.02 \%$, avoiding (avoidance) the risk as much as 38.27 or $40.28 \%$, and transferring (transfer) the risk as much as 2.90 or $3.05 \%$. The average alternative strategies for handling the risk response for (B) technical aspect are bearing (retention) the risk with an achievement of as much as 36.69 or $38.62 \%$, decreasing (reduction) the risk as much as 27.88 or $29.34 \%$, avoiding (avoidance) the risk as much as 19.97 or $21.02 \%$, and transferring (transfer) the risk as much as 10.47 or $11.02 \%$. The average alternative strategy for risk management responses for (C) financial aspect, namely by bearing (retention) the risk with an achievement of as much as 18.58 or at $19.55 \%$, decreasing (reduction) the risk as much as 24.98 or $26.30 \%$, avoiding (avoidance) the risk as much as 35.23 or $37.08 \%$, and transferring (transfer) the risk as much as 16.26 or $17.12 \%$. The average alternative strategies for handling the risk response for (D) construction cultural aspect are bearing (retention) the risk with an achievement of as much as 10.22 , or $10.75 \%$, decreasing (reduction) the risk as much as 8.23 or $8.67 \%$, avoiding (avoidance) the risk as much as 41.91 or at $44.12 \%$, and transferring (transfer) the risk as much as 34.64 or $36.46 \%$. The average alternative strategies for handling the risk response for $(\mathrm{E})$ healthy and safety management aspect are bearing (retention) the risk with an achievement of as much as 80.20 or $84.42 \%$, decreasing (reduction) the risk as much as 14.26 or $15.01 \%$, avoiding (avoidance) the risk as much as 0.00 or of $0.00 \%$, and transferring (transfer) the risk as much as 0.55 or $0.57 \%$. The average alternative strategies for handling the risk response for $(\mathrm{F})$ environmental aspect are bearing (retention) the risk with an achievement of as much as 46.27 or $48.70 \%$, decreasing (reduction) the risk as much as 34.61 or $36.44 \%$, avoiding (avoidance) the risk as much as 3.10 or $3.26 \%$, and transferring (transfer) the risk as much as 11.02 , or $11.60 \%$.

\section{CONCLUSIONS AND SUGGESTION}

\section{A. Conclusions}

From the discussion and analysis results of the research, it can be concluded as follows;

1. The number of risks were identified for the road construction is 281 risks which are grouped into nontechnical aspect 57 risks, technical aspect 39 risks, financial aspect 36 risks, construction cultural aspect 76 risks, healthy and safety management aspect 38 risks and environmental aspect 35 risks.

2. Weight of the objective importance from the indicator on the risk of road construction works, namely cost 0.370 , time 0.252 , quality 0.184 , health and safety management 0.120 , and environmental 0,074 , for the level of objective criteria on cost aspect of non-technical 0,113, technical aspect 0.247 , financial aspect 0.185 , construction cultural aspect 0.304 , health and safety management aspect 0.083 and environmental aspect 0.068 .

3. Around 281 variables were identified where $20 \%$ of the highest risk based on indicator aspects, each nontechnical aspect is 13 risks with the percentage of $23.21 \%, 14$ risks for technical aspect of with a percentage of $25.00 \%, 4$ risks for financial aspect with the percentage of $7.14 \%, 23$ risks for construction cultural aspect with a percentage of $41.07 \%, 2$ risks for health and safety management aspect with the percentage of of $3.57 \%$ and no environmental aspect available. This shows that construction cultural aspect especially with the one that related to corruption is largely affecting the risk of road construction works.

4. The extreme risks were 116 risks or $41.28 \%$, high risk as many as 153 risks or $54.45 \%$, medium risk as much as 12 risks or $4.27 \%$, low risk was not be available. 
5. Allocation risk of road Construction works for the contractor as much as 53.19 or $55.88 \%$, splitted (shared) around 22.30 or $23.58 \%$ and the owner as much as 19.52 or $20.55 \%$

6. The alternative strategy of handling the response risk for road construction projects are bearing (retention) the risk with an achievement of as much as 36.03 or at $38.73 \%$, decreasing (reduction) the risk as much as 19.82 or $19.01 \%$, avoiding (avoidance) the risk as much as 26.47 or at $28.13 \%$, and transferring (transfer) the risk as much as 16.90 or at $15.17 \%$.

\section{B. Suggestion}

1. Assessment and risk management analysis examined only the perspective of the contractor for medium and high qualification; it is expected to have further research to contractors with lower qualification.

2. Risk management which has been searched is from the contractor's perspective; it is expected to continue the research by using the project of owner and the consultant's perspective.

3. Indicators of safety in this study only consider aspect of safety management systems and leave out the variables with technical nature.

4. Environmental indicator has not been classified into large number of human environmental impacts, area that affected, duration of the impact, and how much the impact intensity occurred.

\section{Acknowledments}

We expressed many thanks to all those involved directly or indirectly in completing this paper. especisally thanks for the government, the development agency of construction services (LPJK), the implementer of road construction, and the National Roads Rehabilitation Institution of South Sulawesi province and Hasanuddin University who have supported, and provided an opportunity for authors to conducting this research.

\section{References}

[1] Central Bureau Of Statistics, The Development Of Some Of The Main Indonesian Socio-Economic Indicators Indonesia, Jakarta, 2014.

[2] edyaningsih, R.E. Policies Ministry of Health in the Health and Safety at Work, Papers Occupational Safety and Health Convention, Jakarta, 2010.

[3] Development Institution Of Construction Service, South Sulawesi Province LPJK Report, Makassar, 2015.

[4] Center Office Implementation Of National Road VI, Infrastructure development in South Sulawesi, Makassar, 2013.

[5] Flyvbjerg, B., Holm, M.K.S., Buhl, S.L., "What Causes Cost Overrun in Transport Infrastructure Projects?" Transport Reviews, vol. 24, no. 1, January, pp. 3-18,2004

[6] Hutabarat R., Application of Risk Control. Graduate program, Jakarta, 2008.
[7] Public Works Department, Implementation Of Government Regulation No. 60 Of 2008 Regarding to Internal Control System Of Government, Jakarta, 2008.

[8] Wahyudi I., Sopana. Analysis Of Factors Influencing Corruption At The Local Government Budget Unfortunate Highway, Malang Corruption Watch, 2005.

[9] Erani Yustika A., Infrastructure Development Constrained Corruption, Jakarta,2012.

[10] Kompas. Higene Corporate Health and Safety, Jakarta 2012.

[11] Suma'mur. Higene Company and health work, Jakarta, 2009.

[12] Carlo,Nasfryza. Many Companies Neglect Health and Safety, Environmental Syudy postgraduate Bung Hatta University, 2011.

[13] Public Works Department, Procedures for the Preparation of Construction Health and Safety Public Sector for Service Providers, Jakarta 2000.

[14] Public Works Department, General Guidelines for Environmental Management of Road Sector Impacts, Jakarta,2006.

[15] Asianto. Production Management for Construction Services, .Pradnya Paramita, Jakarta, 2005.

[16] Cooper,F.Dale, and Sthepen G., Project Risk Management Guidelines Managing Risk In Large Projects And Complex Procurements. Jhon Wiley. 2005.

[17] Barrie dan Paulson. Project Management Institute (PMI), 1992.

[18] Ritchie, B. and Marshall, D., Business Risk Management, Chapman \& Hall, London, 1993.

[19] Djamin Pedju M., Integrating Consideration Value Engineering and Risk Management Project Construction Phase Impact On Achieving The Goals and Success of The Project, 2014.

[20] Kerzner H., Project Management A Systems Approach to Planning Scheduling and Controlling 10th Edition, Jhon Wiley, 2009.

[21] Flanagan Roger, and Norman G., Risk Management And Construction. 2003.

[22] Saaty, Thomas L., Fundamental Of Decition Making And Priority Theory With The Analitical Hierachi Procces. University Of Pittsburgh,1994.

[23] Saaty, T. L., Decision Making for Leader: The Analytical Hierarchy Process for Decisions in Complex World,: University of Pittsburgh. Pittburgh, 1993

About Author (s):

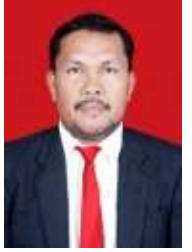

Results of the study, Amount of the risk identified for the construction of the road as much as 281 risks and were grouped into aspect of non-technical 57, technical aspect 39, financial aspect 36, the cultural aspect of the construction 76 , aspect of health and safety management 38 and environmental aspect 35. Weight of importance of objective indicators on the risk of road construction works, namely cost 0.370 , time 0.252 , quality 0.184 , Health and safety management 0.120 , and environmental 0,074 . 